\title{
Timolipoma: Uma Radiografia Pouco Convencional
}

\section{Thymolipoma: An Unconventional Radiography}

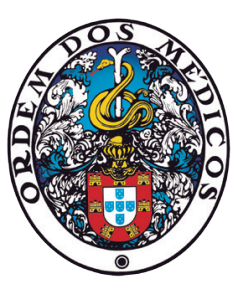

Duarte ROSA $\triangle 1$ ', Sofia Frade SANTOS ${ }^{1}$, João Paulo CONCEIÇÃO E SILVA ${ }^{1}$

Acta Med Port 2020 Mar;33(3):212-212 - https://doi.org/10.20344/amp.11581

Palavras-chave: Criança; Lipoma/diagnóstico por imagem; Neoplasias do Timo/diagnóstico por imagem

Keywords: Child; Lipoma/diagnostic imaging; Thymus Neoplasms/diagnostic imaging

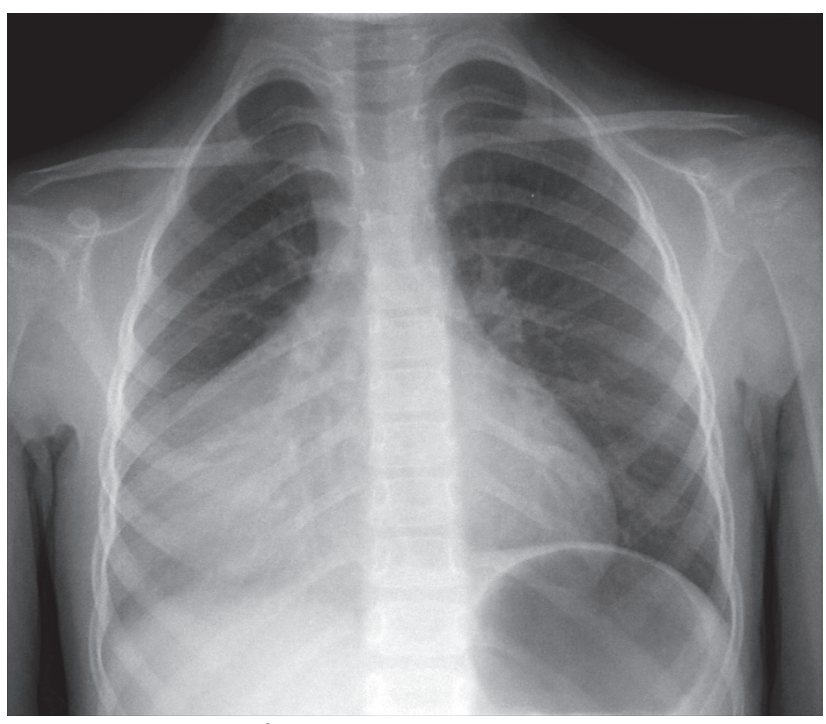

Figura 1 - Radiografia anteroposterior do tórax onde se observa opacidade do hemitórax direito com sinal da silhueta com as estruturas cardíacas

Os autores reportam um caso de uma criança do sexo feminino, com seis anos, observada em contexto de urgência por dispneia. A radiografia convencional do tórax revelou opacidade do hemitórax direito, com sinal da silhueta com as estruturas cardíacas (Fig. 1). A hipótese diagnóstica colocada foi de pneumonia do lobo médio. Dado que não havia alterações laboratoriais que sugerissem patologia infecciosa, foi realizada tomografia computadorizada do tórax, onde se observou lesão tumoral de tecidos moles mediastínica, com componente de gordura macroscópica, estendendo-se à base do hemitórax direito, empurrando o lobo pulmonar inferior direito, sem invadir as estruturas cardiovasculares nem pulmonares. O diagnóstico radiológico foi de timolipoma,

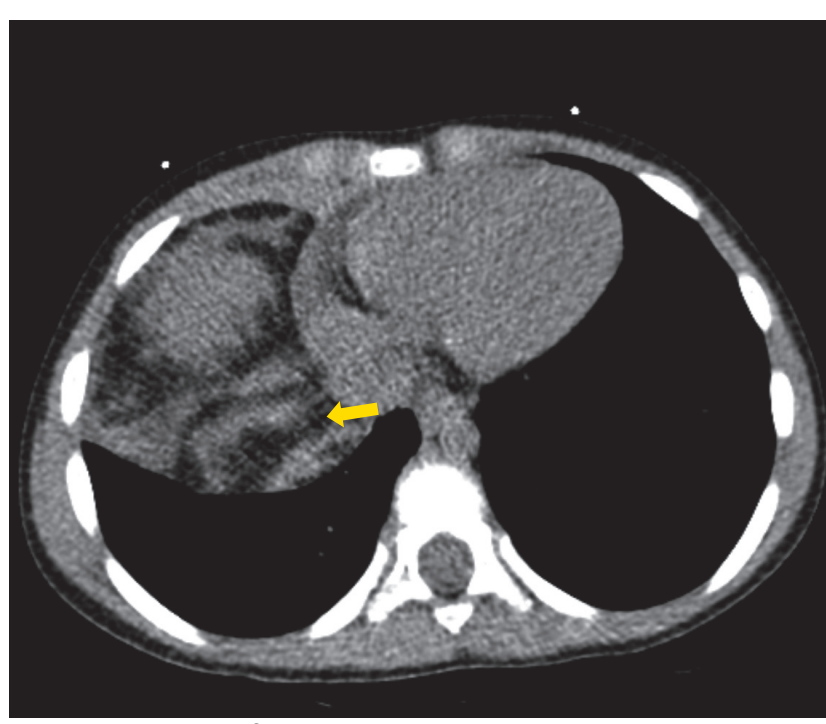

Figura 2 - Tomografia computadorizada do tórax simples, onde se observa lesão com densidade de partes moles e com gordura macroscópica (seta amarela), que não invade estruturas adjacentes

que foi confirmado na avaliação anatomopatológica da peça cirúrgica.

Os timolipomas são tumores tímicos raros, benignos e bem encapsulados. ${ }^{1}$ Podem ocorrer em qualquer idade e os sintomas podem estar relacionados com a compressão das estruturas adjacentes. ${ }^{2}$ São geralmente grandes, mas não invadem as estruturas vizinhas ${ }^{2,3} \mathrm{~A}$ tomografia computorizada torácica geralmente não apresenta dificuldades no diagnóstico, já que é característica a presença de imagem de lesão mista, apresentando densidade de partes moles e de gordura, com ponto de partida mediastínico, empurrando as estruturas vizinhas sem as invadir. ${ }^{1,4}$

PROTECÇÃO DE PESSOAS E ANIMAIS: Os autores declaram que os procedimentos seguidos estavam de acordo com os regulamentos estabelecidos pelos responsáveis da Comissão de Investigação Clínica e Ética e de acordo com a Declaração de Helsínquia da Associação Médica Mundial.

CONFIDENCIALIDADE DOS DADOS: Os autores declaram ter seguido os protocolos do seu centro de trabalho acerca da publicação de dados.

CONSENTIMENTO INFORMADO: Obtido.

CONFLITOS DE INTERESSE: Os autores declaram não ter qualquer conflito de interesse relativamente ao presente artigo.

FONTES DE FINANCIAMENTO: Sem fontes externas de financiamento para a realização deste artigo.

\section{REFERÊNCIAS}

1. Nasseri F, Eftekhari F. Clinical and radiologic review of the normal and abnormal thymus: pearls and pitfalls. RadioGraphics. 2010;30:413-28.

2. Slovis T, Meza M, Kuhn J. Aberrant thymus: MR assessment. Pediatr Radiol. 1992;22:490-2.

3. Siegel M, Glazer H, Wiener J, Molina P. Normal and abnormal thymus in childhood: MR imaging. Radiology. 1989;172:367-71.

4. Mullen B, Richardson JD. Primary anterior mediastinal tumors in children and adults. Ann Thorac Surg. 1986;423:338-45.

1. Serviço de Radiologia. Instituto Português de Oncologia de Lisboa Francisco Gentil. Lisboa. Portugal.

$\triangle$ Autor correspondente: Duarte Rosa. dmscr2004@msn.com

Recebido: 20 de novembro de 2018 - Aceite: 08 de maio de 2019 | Copyright $\odot$ Ordem dos Médicos 2020 